\title{
Reflections of Near-Death Experiences and Deathbed Visions: A Study of Nursing Faculty's Perceptions
}

\author{
Linda Moore, Ed.D., MSN, RN \\ Wayland Baptist University \\ Christopher L. Pate, Ph.D., MPA, CQIA \\ Brooke Army Medical Center
}

\begin{abstract}
Nursing faculty across the United States were surveyed about their knowledge, attitudes, and perspectives of near-death experiences (NDEs) and deathbed visions (DBVs) through web-based administration of the Near-Death Phenomena Knowledge and Attitudes Questionnaire (Thornburg, 1988). Of the approximately 550 responses, $13 \%$ of respondents indicated that they personally had experienced an NDE, 48\% that they have cared for a patient reporting an NDE, and $46 \%$ that they have cared for a patient reporting a DBV. Item-level ordinal logistic regression analysis was used to evaluate the two attitude components of the survey, revealing a complex set of relationships between attitudes, experience, and other individual-level characteristics. The results underscore the importance of ongoing research into near-death phenomena and inclusion of NDEs and DBVs as content areas in nursing curriculum.
\end{abstract}

KEY WORDS: nursing faculty; attitudes; near-death experiences; deathbed visions

Near-death experiences (NDEs) and deathbed visions (DBVs) have been described throughout the annals of history dating back to early beginnings of recorded ethnography (Badham, 1997). However, these experiences have been a primary focus of refereed research for just over the past 40 years (Greyson, 1983; Holden, Greyson, \& James, 2009; Moody, 1975; Ring, 1980). Research in the area of NDEs has

\footnotetext{
Linda Moore, Ed.D., MSN, RN, is associate professor of nursing at Wayland Baptist University in San Antonio, Texas. Christopher L. Pate, Ph.D., MPA, CQIA, is Chief of the Management Analysis Branch, Resource Management Division, Brooke Army Medical Center, Joint Base San Antonio/Fort Sam Houston, Texas. Correspondence regarding this article should be sent to Dr. Moore at email: moorel@wbu.edu.
} 


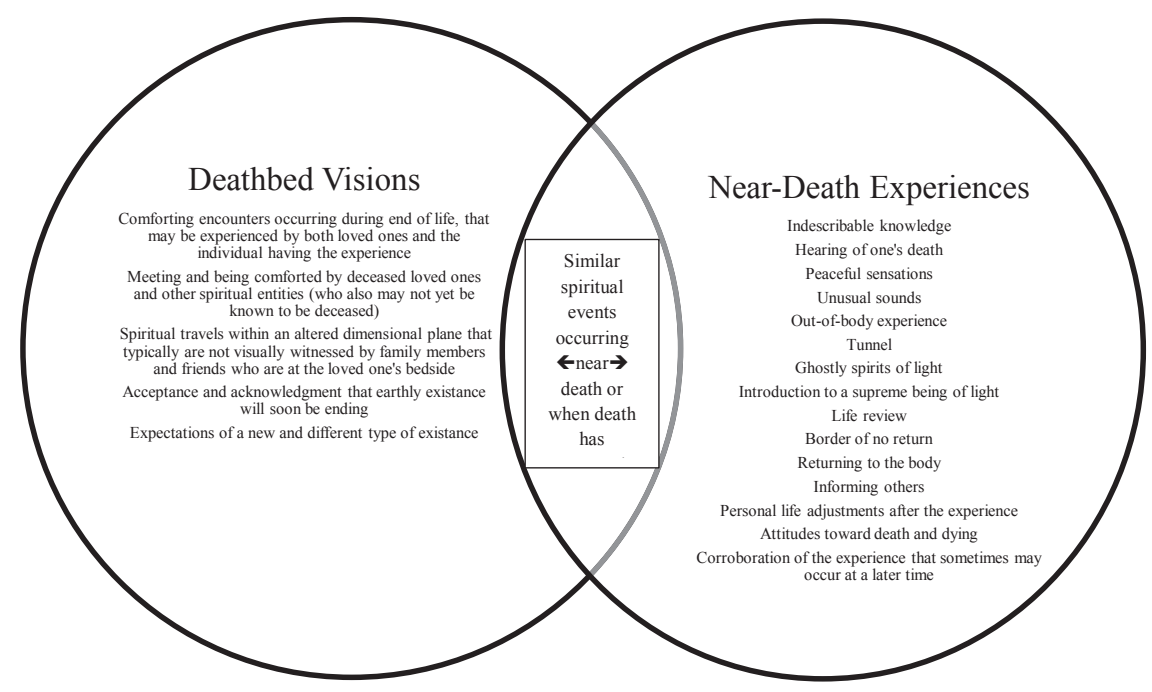

Figure 1. Comparison of DBVs and NDEs (Barbato, 2009; Fox, 2003).

included both qualitative analysis of personal accounts and quantitative studies of NDE contents and aftereffects (Holden et al., 2009). Research in the area of DBVs has been sparse (for example, Osis \& Haraldsson, 1988), yet a growing interest in end-of-life experiences has been gaining momentum over the past 10 years (Fenwick \& Fenwick, 2008; Streit-Horn, 2011). Although conceptual similarities exist between DBVs and NDEs (See Figure 1), a primary difference between the two is related to clinical death: The DBV experiencer is not undergoing clinical death at the time of the vision but is in a terminal state and may be within minutes, hours, days, weeks, or months of dying (Greyson, 1997). End of life events (ELEs), defined as experiences associated with spiritual visions that point toward an afterlife and also include DBVs, have been expressed by experiencers to loved ones and health care personnel; however, up until the last decade, most professionals have discounted the accounts as last wisps of life-states of confusion - and, thus, these anecdotes have only rarely been explored utilizing scientific inquiry (Parnia, 2006).

Military nurse Diane Corcoran (1988) observed that NDEs and DBVs have an enormous impact on both the patient and family members. These events also have substantial meaning for clinical personnel caring for patients experiencing the events (Morris \& Knafl, 2003). The direct care nurse charged with holistic care must be knowl- 
edgeable and accepting of NDEs and DBVs in order to provide culturally competent care to patient and family members (Foster, James, $\&$ Holden, 2009). Because a clinical nurse may be the first licensed healthcare professional to encounter a patient having an NDE or a DBV, knowledge and understanding of these phenomena becomes even more important. Nevertheless, misunderstandings and inadequate knowledge of these phenomena among clinical personnel (Morris \& Knafl, 2003) may prevent the quality of care expected in contemporary healthcare environments.

The importance of ensuring that the direct-care nurse has received instruction that enables exploration of near-death phenomena cannot be underestimated (Brayne, Lovelace, \& Fenwick, 2008). The nursing educator is the individual who provides initial mentoring of the student nurse and prepares the student nurse for a lifelong career in the comprehensive delivery of care to patients and families of patients (McGovern-Billings \& Halstead, 1998). In the process of mentoring students, nursing faculty members who exhibit positive attitudes toward near-death phenomena will likely be more open to exploration and inclusion of content associated with situations involving NDEs and DBVs.

Although nursing knowledge and attitudes associated with NDEs and DBVs are important in providing holistic, culturally competent nursing care, our search of the professional literature-using academically recognized data search engines, including CINAHL Plus with Full Text, Health-Wellness Resource Center, PsycINFO, ProQuest, EBSCO, Religion \& Philosophy Collection, and Google Scholar—failed to yield research focused on comprehensive exploration of knowledge and attitudes toward NDEs or DBVs among nursing educators. We found a few studies in which researchers assessed NDE knowledge of healthcare workers or paraprofessionals and more literature focused on attitudes toward NDEs by healthcare providers, including clergy, hospital nurses, hospice nurses, physicians, and psychologists (Barnett, 1990; Bucher, Wimbush, Hardie, \& Hayes (1997); Corcoran, 1998; Cuncio, 2001; Holden, Oden, Kozlowski, \& Hayslip, 2011; McEvoy, 1990; Moody, 2007; Moore, 1994; Morse, 1983; Oaks, 1981; Royse, 1985; Sabom, 1982; Thornburg, 1988; Walker \& Russell, 1989; Wimbush, F., Hardie, T., \& Haynes, E., 1997). Although Linda Morris and Kathleen Knafl's (2003) did not examine knowledge and attitudes specifically, they examined nursing experiences with NDEs in terms of spiritual and practice-related domains, which have direct implications for clinical practice. We found only one empirically-based study that included 


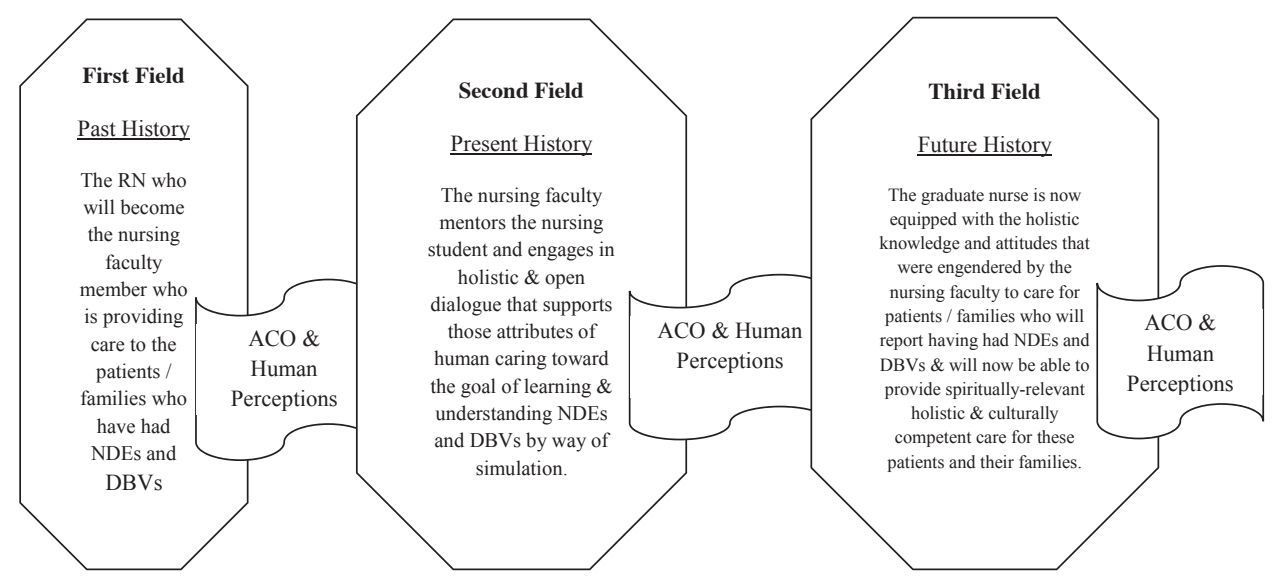

Figure 2. Theoretical framework utilizing Watson's (1985) actual caring occasion and Flew's (2007) concept of human perceptions.

attention to implications for palliative care in regards to end-of-life experiences associated with attitudes toward DBVs (Fenwick, Lovelace \& Brayne, 2007). Furthermore, it is our observation that knowledge of NDEs and DBVs is not typically acquired through undergraduate nursing education because textbooks used in undergraduate education programs lack specific content on these phenomena.

Our research focused on assessing experiences of caring for NDE and DBV patients, as well as knowledge and attitudes toward neardeath phenomena, among nurses who have become nursing educators and who may have provided care for NDE and DBV patients. Specifically, we sought to investigate nurse educators' knowledge and attitudes toward near-death phenomena and reported experiences that the nurses may have encountered.

For the theoretical framework for this study, we used Jean Watson's theory of human caring (1988) coupled with Antony Flew's (2007) concept of human perceptions - whereby an experience is real to the individual who has it (Figure 2). A central element within Watson's theory, the actual caring occasion (ACO), sets the stage whereby the discussion of the existence of NDEs and DBVs became the focal point, creating what Watson (1984) termed the phenomenal matrix. The ACO, a multi-dimensional phenomenological experience, is greater than just the sum of the caring event (NDE or DBV). From Watson's (1985) ACO perspective, individuals engaged in the therapeutic experience are part of the whole caring phenomenon. Individuals experiencing 
the ACO include the nursing faculty, the NDE/DBV patient, the nursing student, and the phenomenological experiences that each of these individuals has experienced and discussed.

\section{Methods}

For this study, we used a non-experimental, cross-sectional research design that included electronic administration of an instrument designed to assess knowledge and attitudes about NDEs. We used this approach to address the following research questions:

-What do nursing faculty members know about NDEs?

-What are the attitudes of nursing faculty members toward NDEs?

- What are the perceptions of nursing faculty members regarding NDEs?

- What are the perceptions of nursing faculty members regarding DBVs?

- How do personal experiences with NDEs and DBVs relate to nursing faculty members' knowledge, beliefs, and attitudes about NDEs and DBVs?

\section{Participants}

Participants were recruited from the National League of Nursing (NLN), a professional nursing organization focusing on evidencebased research and translation of research findings into practice (NLN, 2010). An application was submitted to the research department of NLN, and the primary investigator was allowed to purchase a directory listing of a subset of colleges and universities that were members of the NLN.

Members of the NLN who participated in the study were nursing educators who taught in a variety of nursing academic arenas that included vocational nursing, associate degree, bachelor of science, master of science, and doctoral programs. Using a non-random selection process of NLN accredited schools of nursing that allowed access to nursing faculty members' email addresses, faculties from 19 states and the territory of Guam were targeted to participate in the study. After receiving approval from the Texas A\&M University-Corpus Christi's Institutional Review Board, the primary investigator began a systematic process of accessing nursing faculty email addresses from the identified schools. 


\section{Instruments}

Nina Thornburg's (1988) Near-Death Phenomena Knowledge and Attitudes Questionnaire (NDPKAQ) consists of three distinct components: knowledge of NDEs (Knowledge), attitudes toward NDEs (Attitudes), and attitudes toward caring for NDE patients (Care). The Knowledge component consists of 23 statements with response alternatives of true, false, and undecided. The 23-item Attitudes component and the 20-item Care component consist of five-category Likerttype items with response options of strongly agree, agree, undecided, disagree, and strongly disagree. Piloting her NDPKAQ tool with intensive care nurses, Thornburg (1988) found adequate internal consistency, with reported Cronbach's alpha coefficients of $.83, .84$, and .81 associated with the Knowledge, Attitudes, and Care components, respectively. Content validity was substantiated by individuals whom Thornburg reported were experts in the field of NDE research at that time (Thornburg, 1988; Walker \& Russell, 1989).

For this research study, we developed three additional sections to capture demographic and qualitative information regarding respondents' experiences with NDEs and DBVs. The demographic section included five questions about gender, ethnicity, age, education level, religious/spiritual preference; five questions about experience with NDEs and DBVs; and a single question about teaching or mentoring experience in nursing education. We also created two sections with open-ended questions to provide respondents with the opportunity to describe experiences with NDEs and DBVs. In summary, the six-part survey allowed a combination of quantitative and qualitative measurements and consisted of: (a) demographics, (b) knowledge of NDE, (c) attitudes toward NDE, (d) attitudes toward caring for NDE patients, (e) perspectives on NDEs, and (f) perspectives on DBVs. We developed an online version of the NDPKAQ and pilot tested it prior to conducting the study to ensure its utility. Qualtrics ${ }^{\circledR}(2009)$, a web-based survey tool, was used for survey administration and data collection. Descriptive and inferential analyses were conducted using Minitab ${ }^{\circledR}(2010)$.

\section{Results}

\section{Demographics}

Out of 3,673 nursing faculty members to whom we distributed questionnaires, 588 accessed the survey and, of these, 17 elected not to participate, leaving $571(15.55 \%)$ participants who responded to enough 
of the survey to make their responses usable. The majority of participants were female (94\%), and the reported age of respondents ranged from 28 to 76 years with a mean of 52.99 years and a $95 \%$ confidence interval of [52.20, 53.77]. Over half of respondents were master's-prepared nurses, and $25 \%$ were doctorate-prepared. Of the respondents who identified ethnicity, 442 (80\%) indicated Caucasian, 38 (7\%) indicated African-American, 25 (5\%) indicated blended ethnicity, 22 (4\%) indicated Hispanic, and the remaining 22 (4\%) indicated American Indian, Asian, or other. Regarding religious affiliation, $88 \%$ of participants indicated Christian, and the remaining $12 \%$ reported being of various belief systems, including Muslim, Universalist, Hindu, Buddhist, Atheist, Wiccan, and Scientist. Regarding career experience, of the 552 participants who responded, 256 (46\%) indicated that their career had included teaching or mentoring entry-level licensed nurses.

Regarding experience with NDEs and DBVs, respondents were provided with five questions in a yes/no format that assessed personal, familial, or patient-related experiences. Some participants reported they had personally had an NDE $(71 ; 13 \%)$, had cared for a patient who reported an NDE (262; 48\%), had a family member who reported an NDE (127; 23\%), had provided care for a patient or family member who reported a DBV $(250 ; 46 \%)$, and had personally experienced a DBV or had a family member who reported a DBV $(151 ; 21 \%)$.

\section{NDE Knowledge}

Knowledge scores were calculated using Thornburg's (1988) scoring procedure that she developed with the original NDPKAQ, which includes reverse-scoring for false items. By individual test item, correct responses ranged from $3.5 \%$ to $76.9 \%$, whereas the percentage of undecided responses by test item ranged from $16.1 \%$ to $83.7 \%$ (see Table 1). Although use of individual item response theory (IRT) was not a central objective of the study, we used the theoretical approach to summarize results by the proportion of correct responses, which is typical in the analysis of polychotomous scoring of item responses for nominally scaled data (Drasgow \& Hulin, 1990). With 0 representing incorrect response, .5 uncertainty, and 1 correct response, the mean score (i.e., proportion correct) across all 23 items for the 519 nurse educators who completed at least one item on the Knowledge component was 0.37 with a standard deviation of 0.24 . Evaluation of the missing item-level responses (i.e., those that were skipped) revealed a negligible impact on the component mean: Using complete cases for 
Table 1 NDE Knowledge Component Summary by Response Counts and Percentages

\begin{tabular}{|c|c|c|c|c|c|c|c|c|}
\hline $\begin{array}{l}\text { Item } \\
\text { Number }\end{array}$ & $\begin{array}{l}\text { Number } \\
\text { "True" } \\
\text { Response }\end{array}$ & $\begin{array}{c}\% \\
\text { True }\end{array}$ & $\begin{array}{c}\text { Number } \\
\text { "False" } \\
\text { Responses }\end{array}$ & $\%$ False & $\begin{array}{c}\text { Number } \\
\text { "Unde- } \\
\text { cided" } \\
\text { Responses }\end{array}$ & $\begin{array}{c}\% \\
\text { Undecided }\end{array}$ & $\begin{array}{c}\% \\
\text { Correct }\end{array}$ & Total \\
\hline 1 & 197 & $38 \%$ & 188 & $36 \%$ & 129 & $25 \%$ & $36 \%$ & 514 \\
\hline 2 & 296 & $57 \%$ & 65 & $13 \%$ & 148 & $29 \%$ & $57 \%$ & 509 \\
\hline 3 & 365 & $70 \%$ & 16 & $3 \%$ & 132 & $25 \%$ & $70 \%$ & 513 \\
\hline 4 & 67 & $13 \%$ & 62 & $12 \%$ & 384 & $74 \%$ & $13 \%$ & 513 \\
\hline 5 & 42 & $8 \%$ & 80 & $15 \%$ & 389 & $75 \%$ & $15 \%$ & 511 \\
\hline 6 & 267 & $51 \%$ & 94 & $18 \%$ & 144 & $28 \%$ & $51 \%$ & 505 \\
\hline 7 & 212 & $41 \%$ & 155 & $30 \%$ & 146 & $28 \%$ & $41 \%$ & 513 \\
\hline 8 & 18 & $3 \%$ & 63 & $12 \%$ & 430 & $83 \%$ & $3 \%$ & 511 \\
\hline 9 & 11 & $2 \%$ & 330 & $64 \%$ & 169 & $33 \%$ & $64 \%$ & 510 \\
\hline 10 & 33 & $6 \%$ & 263 & $51 \%$ & 215 & $41 \%$ & $51 \%$ & 511 \\
\hline 11 & 259 & $50 \%$ & 37 & $7 \%$ & 213 & $41 \%$ & $50 \%$ & 509 \\
\hline 12 & 85 & $16 \%$ & 120 & $23 \%$ & 307 & $59 \%$ & $23 \%$ & 512 \\
\hline 13 & 355 & $69 \%$ & 17 & $3 \%$ & 138 & $27 \%$ & $69 \%$ & 512 \\
\hline 14 & 136 & $26 \%$ & 31 & $6 \%$ & 344 & $66 \%$ & $6 \%$ & 511 \\
\hline 15 & 95 & $18 \%$ & 81 & $16 \%$ & 333 & $64 \%$ & $16 \%$ & 509 \\
\hline 16 & 195 & $38 \%$ & 177 & $34 \%$ & 137 & $26 \%$ & $38 \%$ & 509 \\
\hline 17 & 393 & $76 \%$ & 35 & $7 \%$ & 83 & $16 \%$ & $76 \%$ & 511 \\
\hline 18 & 66 & $13 \%$ & 79 & $15 \%$ & 366 & $71 \%$ & $15 \%$ & 511 \\
\hline 19 & 27 & $5 \%$ & 66 & $13 \%$ & 419 & $81 \%$ & $5 \%$ & 512 \\
\hline 20 & 37 & $7 \%$ & 78 & $15 \%$ & 396 & $76 \%$ & $15 \%$ & 511 \\
\hline 21 & 13 & $3 \%$ & 260 & $50 \%$ & 237 & $46 \%$ & $50 \%$ & 510 \\
\hline 22 & 375 & $72 \%$ & 9 & $2 \%$ & 124 & $24 \%$ & $72 \%$ & 508 \\
\hline 23 & 125 & $24 \%$ & 115 & $22 \%$ & 270 & $52 \%$ & $25 \%$ & 510 \\
\hline
\end{tabular}

Note: Shaded cells indicate correct responses by item. Total $\mathrm{n}=519$ for this component and "Total" column reflects the number of non-missing responses. 
the component resulted in a mean score of 0.38 with a standard deviation of 0.24 . Thus, on average, nurse educators' responses on the Knowledge component were more incorrect than correct.

The lowest percentages of correct responses were found for the following three false items: 8. Suicide-induced NDEs are unpleasant (3\% correct); 14 . There are no significant differences between NDEs related by those who are not given drugs (6\% correct); and 19. Alcohol intoxication while close to death diminishes the likelihood of a NDE (5\% correct). The highest percentages of correct responses were found for the following four true items: 13 . Over $80 \%$ of NDE survivors report a greater appreciation for life and of attempting to live more fully following a NDE (69\% correct); 3 . A point may be described by the NDE survivor where the person was told or had the choice to return to his/her body (70\% correct); 22 . The NDE has a powerful effect on client's subsequent belief in an afterlife (72\% correct); and 17 . The NDE has been described as being peaceful, quiet, and without sensation of pain $(76 \%$ correct).

Although the distribution of raw scores by individual respondent displayed an approximately normal shape, the distribution was leftskewed because of zero scores: Approximately 5\% of the individuals scored zero on Knowledge $\left(A^{2}=4.69, p<.005\right)$. The respondent mean score was 8.70 out of 23 , with a $95 \%$ confidence interval of [8.35, 9.04]. Regression analysis of individual raw scores on age, ethnicity (Caucasian versus otherwise), education level (master's and doctoral level versus otherwise), religion (Judeo-Christian versus otherwise), and all five dummy coded NDE/DBV experience categories yielded an adjusted $R^{2}$ of $3.0 \%(F=3.32, p<.009)$. Two of the predictors were significant given $\alpha$ levels of .10: The average score for nurse educators at the doctoral level was 1.01 points higher than those with education levels up to and including the bachelor's degree $(b=1.01, p=.085)$, whereas the average score for nurse educators reporting that they had cared for patients or family members experiencing DBVs (DBV Patient or Family Care) was .947 points lower than those that did not report this experience $(b=-.947, p=.031)$.

\section{NDE Attitudes}

Participants' responses to Attitude items are summarized in Table 2. Out of a possible total Attitude score of $100 \%$ calculated by the number of responses that strictly fall in the most positive or most negative categories (strongly agree or strongly disagree) divided by the non- 
Table 2 General Attitude Component: Summary Responses by Response Category

\begin{tabular}{|c|c|c|c|c|c|c|c|}
\hline Item & $\begin{array}{l}\text { Strongly } \\
\text { Agree }\end{array}$ & Agree & Neutral & Disagree & $\begin{array}{l}\text { Strongly } \\
\text { Disagree }\end{array}$ & $n$ & Median \\
\hline 1 & 102 & 212 & 159 & 15 & 8 & 496 & 2 \\
\hline 2 & 9 & 35 & 99 & 253 & 101 & 497 & 4 \\
\hline 3 & 33 & 137 & 247 & 73 & 6 & 496 & 3 \\
\hline 4 & 123 & 260 & 90 & 19 & 5 & 497 & 2 \\
\hline 5 & 78 & 192 & 166 & 51 & 7 & 494 & 2 \\
\hline 6 & 177 & 269 & 87 & 17 & 1 & 491 & 2 \\
\hline 7 & 99 & 270 & 99 & 25 & 3 & 496 & 2 \\
\hline 8 & 1 & 6 & 70 & 267 & 149 & 493 & 4 \\
\hline 9 & 2 & 6 & 51 & 199 & 234 & 492 & 5 \\
\hline 10 & 112 & 216 & 141 & 11 & 7 & 487 & 2 \\
\hline 11 & 3 & 13 & 25 & 182 & 272 & 495 & 5 \\
\hline 12 & 79 & 214 & 157 & 38 & 7 & 495 & 2 \\
\hline 13 & 6 & 55 & 343 & 78 & 15 & 497 & 3 \\
\hline 14 & 73 & 303 & 101 & 11 & 5 & 493 & 2 \\
\hline 15 & 3 & 31 & 269 & 158 & 36 & 497 & 3 \\
\hline 16 & 3 & 9 & 81 & 257 & 145 & 495 & 4 \\
\hline 17 & 34 & 171 & 200 & 78 & 13 & 496 & 3 \\
\hline 18 & 2 & 8 & 118 & 241 & 125 & 494 & 4 \\
\hline 19 & 1 & 10 & 58 & 247 & 179 & 495 & 4 \\
\hline 20 & 131 & 297 & 59 & 10 & 0 & 497 & 2 \\
\hline 21 & 62 & 294 & 121 & 18 & 1 & 496 & 2 \\
\hline 22 & 45 & 203 & 195 & 43 & 8 & 494 & 2 \\
\hline 23 & 37 & 192 & 196 & 65 & 7 & 497 & 3 \\
\hline
\end{tabular}

Note: Shaded cells indicate most positive attitude. Table $\mathrm{n}$ represents non-missing responses; total $\mathrm{n}=499$ for component. 
missing responses for individual item, for the 499 nurse educators who completed at least one item on the component, scores ranged from $1.2 \%$ (13. Nurses should be the first to hear of their client's NDE report) to $54.9 \%$ (11. Students should not be allowed to work with clients who report NDE) with a mean of $20.8 \%$ and a $95 \%$ confidence interval of $[14.7,26.9]$. Positive scoring of the top two (bottom) categories indicate that, on average, nurse educators' attitudes towards NDEs leaned strongly toward the positive: The percentage of positive responses by item averaged $66.1 \%$ with a $95 \%$ confidence interval of [57.1, 75.2].

Over half of the participants agreed that course content about neardeath phenomena should be included in nursing curriculum; however, the majority stated that it should not necessarily be the nurse who hears about the experience first. Most participants indicated that stories about near-death phenomena did not frighten them. In the questionnaire section on attitude toward caring for an NDE patient, participants expressed uncertainty that NDE stories make them feel less afraid of death. Participants agreed that open dialogue with patients experiencing NDEs should be documented in the medical record. Participants also affirmed that students should be encouraged to engage in near-death research.

Exploratory ordinal logistic regression analysis was conducted to evaluate the relationship between item responses, demographic variables, and NDE/DBV experiences. Predictors in the model included age (years), sex, religion, ethnicity, education level, and NDE/DBV experiences. With the exception of years of age, dummy coding was used for all categorical predictors, where (a) sex was coded as $1=$ female, 0 = otherwise; (b) ethnicity was coded as $1=$ Caucasian, $0=$ otherwise; (c) education was coded as $1=$ masters, $0=$ otherwise; doctoral $=1$, $0=$ otherwise; (d) religion was coded as $1=$ Judeo-Christian, $0=$ otherwise; and (e) all NDE/DBV experiences dummy coded for each experience category (i.e., personally had NDE coded as 1, $0=$ otherwise, etc.). Coding of the ordinal response followed the convention that the response "strongly agree" $=1$, "agree" $=2$, "undecided" $=3$, "disagree" $=4$, and "strongly disagree" $=5$, with the latter category serving as the referent category in the coding scheme. We first examined overall model significance for each regression and are reporting the by-item regression results on those that had overall $p$-values $<.05$.

Table 3 provides goodness of fit statistics $(G)$ for overall model significance, associated $p$-values, and listing of variables with significant Wald statistics $(p<.05)$. Of the 23 regressions, 12 yielded model fit statistics below the threshold. The regression coefficients listed 
Table 3 General Attitude Component: Ordinal Regression Analysis Summaries by Significant Predictors and Model Significance

\begin{tabular}{|c|c|c|}
\hline Item & Predictors with Significant Wald Tests & Model Significance \\
\hline 2 & DBV - Patient/Family Care $(b=.599, p=.009)$ & $\begin{array}{l}G=35.24 \\
p=.005\end{array}$ \\
\hline 3 & $\begin{array}{l}\text { Ethnicity }(b=.521, p=.014) ; \text { Religion }(b=-.465 \\
p=.056) ; \mathrm{DBV}-\text { Personal/Family } \operatorname{Exp}(b=-.375 \\
p=.090)\end{array}$ & $\begin{array}{l}G=25.179 \\
p=.005\end{array}$ \\
\hline 4 & $\begin{array}{l}\text { NDE - Family Member }(b=. .523, p=.046) ; \mathrm{DBV} \text { - } \\
\text { Patient/Family Care }(b=-.435, p=.080)\end{array}$ & $\begin{array}{l}G=19.056 \\
p=.040\end{array}$ \\
\hline 7 & $\begin{array}{l}\text { Education (doctoral degree, } b=1.252, p<.001) \text {; DBV - } \\
\text { Patient/Family Care }(b=.143, p=.036)\end{array}$ & $\begin{array}{l}G=33.602 \\
p<.001\end{array}$ \\
\hline 8 & $\begin{array}{l}\text { Education (doctoral degree, } b=.693, p=.031) \text {; DBV - } \\
\text { Patient/Family Care }(b=.668, p=.006)\end{array}$ & $\begin{array}{l}G=25.654 \\
p=.004\end{array}$ \\
\hline 9 & $\begin{array}{l}\text { NDE - Patient Care }(b=.620, p=.005) ; \mathrm{DBV} \text { - Patient/ } \\
\text { Family Care }(b=.534, p=.014) ; \mathrm{DBV} \text { - Personal/ } \\
\text { Family } \operatorname{Exp}(b=.419, p=.047)\end{array}$ & $G=18.952, p=.041$ \\
\hline
\end{tabular}

11 Ethnicity $(b=.623, p=.007)$; Education (doctoral degree, $\quad G=31.950, p<.001$ $b=.777, p=.015)$; NDE - Family Member

$(b=-.614, p=.012)$; DBV - Patient/Family Care

$(b=-.791, p=.001)$

12 Ethnicity $(b=.554, p=.010)$; Education (doctoral degree, $\quad G=38.959$, $b=-.798, p=.008) ;$ DBV - Patient/Family Care $(b=-.589, \quad p<.001$ $p=.009)$

13 Education (doctoral degree, $b=.711, p=.027$ ); NDE -

$G=30.828$, Family Member $(b=-.546, p=.036)$; DBV - Patient/Fam- $p<.001$ ily Care $(b=-.860, p=.001)$

15 DBV - Patient/Family Care $(b=-.622, p=.005)$

$G=21.167, p=.020$

$16 \operatorname{Sex}(b=-.935, p=.020) ;$ Ethnicity $(b=-.588$,

$p=.007) ; \mathrm{DBV}$ - Patient/Family Care $(b=.445$,

$G=40.041, p<.001$ $p=.050)$

17 Ethnicity $(b=.839, p<.001)$; NDE - Personal Exp

$G=29.477, p=.001$ $(b=-.712$, $p=.010)$; DBV - Patient/Family Care $(b=-.469$, $p=.034)$

18 Ethnicity $(b=-.795, p<.001)$; Education (doctoral $G=39.512, p<.001$ degree, $b=-.739, p=.018$ ); NDE - Family Member $(b=.498, p=.041)$; DBV - Patient/Family Care $(b=.796, p=.001)$

20 Ethnicity $(b=-.910, p<.001)$; DBV - Patient/Family Care $G=42.164, p<.001$ $(b=.864, p<.001)$ 
in the table refer to the change in the logit for a unit change in the predictor (Hosmer \& Lemeshow, 1989; O'Connell, 2006). Coefficients can be changed to odds-ratios through exponentiation of and-given Minitab's operationalization of the ordinal regression model-positive coefficients indicate greater association with the higher ranked response category, with "strongly agree" assigned as the highest ranked category. In the analysis of Item 1 , for instance, education (master's degree) was a significant predictor in a model with an overall significance of $p<.001(G=35.240)$. The estimated slope coefficient of 0.572 translates to an odds-ratio of 1.77 , which is 1.77 times the odds for the omitted category in the agree direction rather than the disagree direction: Master's prepared nurses were more likely to select the higher ranked response category compared to other response categories (i.e., "strongly agree" versus "agree," "strongly agree versus "neutral," agree" versus "neutral," and so on) than nurses in the referent category, which included licensed practical nurses, licensed vocational nurses, diploma level RNs, associate degree RNs, BSNs, and those listed as "other." Regression models on the following items were significant at the prescribed threshold:

Item 1: Students should be encouraged to carry out research dealing with Near-Death phenomena.

Item 5: A course dealing with Near-Death phenomena should be available to nursing students.

Item 6: Some clients are reluctant to report their NDEs.

Item 8: Most clients who have NDEs have underlying psychological problems.

Item 9: Stories I have heard about Near-Death phenomena frighten me.

Item 11: Students should not be allowed to work with clients who report NDEs.

Item 12: Students would very likely benefit from taking a course dealing with Near-Death phenomena.

Item 14: Continuing education programs should be developed to help nurses work with clients who have had NDEs.

Item 16: An in-service conference on Near-Death phenomena is a waste of valuable time.

Item 17: Courses dealing with Near-Death phenomena should be included in nursing curricula.

Item 18: Most of what clients remember of their NDEs is wishful thinking.

Item 20: Clients need to be reassured that their NDEs are normal, and do not indicate psychological imbalances. 
Although no consistent pattern emerged across the regression models, education, religion, sex, ethnicity, and NDE/DBV experiences were significant with respect to individual item responses in the general attitudes component of the NDPKAQ. Of the predictors, DBV - Patient/ Family Care was significant in 10 of the items (Items 2, 4, 7, 8, 9, 11, $12,13,15$, and 16). In seven of the items, participants were less likely to select responses associated with positive attitudes $(2,4,7,9,12$, 13 , and 16$)$, whereas in three of the items $(8,11,15)$ participants were more likely to select positive attitude responses versus individuals in the referent group (i.e., those not in the DBV - Patient/Family Care group). Similarly, responses from nurse educators that were doctorally trained were significantly different than nurse educators with education levels at the master's level or lower; however, the pattern of responses was not consistent across items. In three of the items $(8,11$, 12 ), the doctorally trained nurses were more likely to select more positive attitude responses, whereas in two of the items $(7,13)$ the doctorally trained nurses were less likely to select positive attitude response categories. Ethnicity was a significant predictor in four of the items, with white nurses more likely to select positive attitude responses in three items $(3,12,16)$ and less likely to select positive attitudes in item 11. Nurse educators who reported familial experience with an NDE (NDE - Family Member) were less likely to select positive attitude responses in items 4 and 13, whereas individuals in this group were more likely to select positive attitude response categories in item 11. With item 3, individuals classified as Judeo-Christian and individuals reporting either a personal or familial experience with a DBV (DBV - Personal/Family) were less likely to select positive attitude responses versus their respective referent categories. Females were more likely to select positive attitude responses with item 16.

\section{Care of NDE Patients}

Participants' responses to Care items are summarized in Table 4. Out of a possible total Care score of $100 \%$ calculated by the number of responses that strictly fall in the most positive or most negative categories (strongly agree or strongly disagree) divided by the nonmissing responses for individual item, for the 479 nurse educators who completed at least one item on the component, scores ranged from $5.1 \%$ (6. Nurses should not postpone talking about NDEs with a client even if his or her condition is unstable) to $64.7 \%$ (4. Clients who have NDEs should have the same quality of care as clients who do not have 
MOORE, ED.D., MSN, RN \& PATE, PH.D., MPA, CQIA

Table 4 Attitudes Toward Caring Component: Summary Responses by Response Category

\begin{tabular}{|c|c|c|c|c|c|c|c|}
\hline Item & $\begin{array}{c}\text { Strongly } \\
\text { Agree }\end{array}$ & Agree & Neutral & Disagree & Strongly & $n$ & Median \\
\hline 1 & 13 & 26 & 67 & 255 & 118 & 479 & 4 \\
\hline 2 & 3 & 7 & 67 & 267 & 131 & 475 & 4 \\
\hline 3 & 29 & 236 & 178 & 28 & 6 & 477 & 2 \\
\hline 4 & 308 & 145 & 19 & 2 & 2 & 476 & 1 \\
\hline 5 & 1 & 17 & 109 & 239 & 108 & 474 & 4 \\
\hline 6 & 24 & 168 & 164 & 105 & 12 & 473 & 2 \\
\hline 7 & 3 & 23 & 94 & 233 & 123 & 476 & 4 \\
\hline 8 & 282 & 187 & 8 & 0 & 0 & 477 & 1 \\
\hline 9 & 28 & 215 & 138 & 74 & 22 & 477 & 2 \\
\hline 10 & 50 & 234 & 177 & 10 & 3 & 474 & 2 \\
\hline 11 & 235 & 226 & 12 & 3 & 0 & 476 & 2 \\
\hline 12 & 108 & 256 & 84 & 23 & 6 & 477 & 2 \\
\hline 13 & 297 & 166 & 13 & 1 & 0 & 477 & 1 \\
\hline 14 & 87 & 206 & 165 & 16 & 1 & 475 & 2 \\
\hline 15 & 55 & 148 & 223 & 36 & 17 & 479 & 3 \\
\hline 16 & 2 & 3 & 49 & 215 & 207 & 476 & 4 \\
\hline 17 & 84 & 205 & 183 & 5 & 1 & 478 & 2 \\
\hline 18 & 3 & 7 & 16 & 193 & 259 & 478 & 5 \\
\hline 19 & 31 & 142 & 285 & 18 & 1 & 477 & 3 \\
\hline 20 & 7 & 3 & 40 & 176 & 251 & 477 & 5 \\
\hline
\end{tabular}

Note: Shaded cells indicate most positive attitude. Table $\mathrm{n}$ represents non-missing responses; total $\mathrm{n}=479$ for component .

NDEs) with a mean of $29.5 \%$ and a $95 \%$ confidence interval of [19.8, 39.3]. Positive scoring of the top two (bottom) categories indicate that, on average, nurse educator's attitudes towards caring leaned strongly toward the positive: The percentage of positive responses by item averaged $72.6 \%$ with a $95 \%$ confidence interval of [63.1, 82.3].

The majority of study participants indicated positive attitudes to- 
Table 5 Attitudes Toward Caring Component: Ordinal Regression Analysis Summaries by Significant Predictors and Model Significance

\begin{tabular}{|c|c|c|}
\hline Item & Predictors with Significant Wald Tests & Model Significance \\
\hline 2 & DBV - Patient/Family Care $(b=.599, p=.009)$ & $G=24.987, p=.005$ \\
\hline 3 & $\begin{array}{l}\text { Ethnicity }(b=.521, p=.014) \text {; Religion }(b=-.465 \\
p=.056) ; \text { DBV - Personal/Family } \operatorname{Exp}(b=-.375, p=.090)\end{array}$ & $G=25.179, p=.005$ \\
\hline 4 & $\begin{array}{l}\text { NDE - Family Member }(b=. .523, p=.046) ; \mathrm{DBV} \text { - } \\
\text { Patient/Family Care }(b=-.435, p=.080)\end{array}$ & $G=19.056, p=.040$ \\
\hline 7 & $\begin{array}{l}\text { Education (doctoral degree, } b=1.252, p<.001) \\
\text { DBV - Patient/Family Care }(b=-.143, p=.036)\end{array}$ & $G=33.602, p<.001$ \\
\hline 8 & $\begin{array}{l}\text { Education (doctoral degree, } b=.693, p=.031) \\
\text { DBV - Patient/Family Care }(b=-.668, p=.006)\end{array}$ & $G=25.654, p=.004$ \\
\hline 9 & $\begin{array}{l}\text { NDE - Patient Care }(b=.620, p=.005) ; \mathrm{DBV} \text { - Patient/ } \\
\text { Family Care }(b=.534, p=.014) ; \mathrm{DBV} \text { - Personal/Family } \\
\operatorname{Exp}(b=.419, p=.047)\end{array}$ & $G=18.952, p=.041$ \\
\hline
\end{tabular}

11 Ethnicity $(b=.623, p=.007)$; Education (doctoral degree, $G=31.950, p<.001$ $b=.777, p=.015)$; NDE - Family Member $(b=-.614$,

$p=.012)$; DBV - Patient/Family Care $(b=-.791, p=.001)$

12 Ethnicity $(b=.554, p=.010)$; Education (doctoral degree, $b=-.798, p=.008) ;$ DBV - Patient/Family Care $(b=-.589$, $p=.009)$

13 Education (doctoral degree, $b=.711, p=.027$ ); $\mathrm{NDE}$

- Family Member $(b=-.546, p=.036)$; DBV - Patient/

$G=30.828, p=.001$

Family Care $(b=-.860, p=.001)$

15 DBV - Patient/Family Care $(b=-.622, p=.005)$

$G=21.167, p=.020$

$16 \operatorname{Sex}(b=-.935, p=.020) ;$ Ethnicity $(b=-.588, p=.007)$;

DBV - Patient/Family Care $(b=.445, p=.050)$

$G=40.041, p<.001$

17 Ethnicity $(b=.839, p=.000)$; NDE - Personal Exp

$G=29.477, p=.001$

$(b=-.712, p=.010) ;$ DBV - Patient/Family Care

$(b=-.469, p=.034)$

18 Ethnicity $(b=-.795, p<.001)$; Education (doctoral degree, $b=-.739, p=.018)$; NDE - Family Member $(b=.498$, $p=.041)$; DBV - Patient/Family Care $(b=.796, p=.001)$

20 Ethnicity $(b=-.910, p<.001)$; DBV - Patient/Family Care $(b=.864, p<.001)$

$G=42.164, p<.001$ 
ward caring for a patient who reports an NDE. Participants indicated that they should listen attentively to patients' descriptions of their NDEs and feel that these patients deserve to have the same quality of care as patients who do not have NDEs. Most participants indicated that they would welcome the opportunity to work with a patient who had an NDE.

Evaluation of the relationship between personal/professional characteristics, NDE/DBV experiences, and responses on the fourth component of NDPKA followed the same approach as presented previously. We used item-level ordinal logistic regression with model level significance set at $p=.05$ as a threshold and present variables, coefficients, $p$-values, and model statistics for those regressions beyond the threshold. Of the 20 regressions, 14 produced significant $G$ statistics (see Table 5). Regressions on the following questionnaire items yielded significant $G$ statistics:

Item 2: An in-service program on NDEs would be a waste of time.

Item 3: Clients are often aware of resuscitation activities even after respiration and circulation cease.

Item 4: Clients who have NDEs should have the same quality of care as clients who do not have NDEs.

Item 7: Nurses should not interview post-CPR clients about their NDEs without supervision of a physician.

Item 8: I should listen attentively to any NDE report and allow the client to complete the story.

Item 9: Clients who are preoccupied with their NDEs should be referred for professional help.

Item 11: Clients should be able to share their feelings and recollections about their NDEs with whomever they feel most comfortable.

Item 12: I would attend a Near-Death educational program offered by NLN or other professional nursing organization.

Item 13: It is important for me to be nonjudgmental of what I hear no matter how incredible it may seem.

Item 15: Hearing a client's NDE makes me less afraid of death.

Item 16: Clients are making up stories when they report their NDEs.

Item 17: I would like to work with a client who has had a NDE.

Item 18: Clients' reports of their NDEs should be ignored.

Item 20: I would not want to work with a client who has had a NDE.

As before, no consistent pattern emerged with respect to significance of individual covariates; however, a predominant factor in driving attitudes towards caring for patients who have had an NDE was an individual's experience with DBVs and NDEs. Although regres- 
sion coefficients were typically in the direction of the most positive response for the respective item, among some test items the estimated coefficients for the NDE and DBV experience categories frequently ran counter to other groups. In addition to the variables that emerged in the general attitudes section, respondent sex also emerged as a significant predictor in one of the item regressions.

Of the predictors, DBV - Patient/Family Care was significant in 13 of the items (Items 2, 4, 7, 8, 9, 11, 12, 13, 15, 16, 17, 18, 20). In all but items $2,16,18$ and 20, responses of participants who reportedly had cared for a patient or family member with a DBV represented more negative attitudes compared with those that reportedly had not cared for a patient or family member with a DBV. Ethnicity was a significant predictor in 7 items $(3,11,12,16,17,18,20)$ with white nurse educators' responses representing more positive attitudes than non-white. Doctorally prepared nurses were more likely to select positive attitude responses in items 8,11, 13 and 18, whereas they were less likely to select positive attitude responses in items 7 and 12 versus nurses with less educational preparation. Nurse educators reporting familial experience with NDEs were less likely to select positive attitude responses in items $4,11,13$, and 18 . Nurse educators reporting either personal or familial experience with DBVs (DBV - Personal/Family Exp) were more likely to select positive attitudes with item 9 and less likely to select positive attitude responses with item 3 . Individuals classified as Judeo-Christian were less likely to select positive attitude responses with item 3, and individuals reporting patient care experience with NDEs (NDE - Patient Care) were more likely to select positive attitude responses in item 9 versus nurses that did not report patient care experience with NDEs. Nurse educators classified as those with a personal NDE were less likely to select positive attitudes versus those not classified with this experience. Female nurse educators were more likely to select positive attitudes in item 16.

\section{Selected Narratives}

In part five of the questionnaire, we asked participants to write out accounts of NDEs that they were aware of. Again, not all participants elected to respond to this section, but of those who did, a total of 262 (45.88\%) participants reported either single or multiple NDE anecdotes. In-depth analysis of the open-ended responses will be evaluated through thematic content analysis in a pending research study. Of those participants who responded, 21 (8\%) shared their personal NDE 
accounts. Below are samples of just a few of the hundreds of NDE accounts of the nurses who responded:

I had a report from a religious Sister who told me that twice she had a NDE. She witnessed CPR on her body and then "went to the pearly gates." She described it as following the light, very beautiful and peaceful and was greeted by her dog that had died a few years before. She told me that someone we lost and loved would greet us and escort us.

A patient for whom I cared for was being resuscitated and when the patient was revived was able to recall every event that took place during CPR and the people that were in the room doing CPR. She described looking down on the event on herself and being able to see everything amidst very bright white light. She also described feeling most at peace.

As a pediatric oncology nurse working in an intensive care area I have had children near death reveal and share NDEs. One example I can think of is the 11 year old girl near death saying that Jesus was at the foot of her bed and he made her feel like everything was going to be ok. The remarkable part of the story is her mother told me that she didn't know her daughter even knew who Jesus was. They did not practice any type of religion in the home. The daughter died within hours of that incident.

My grandmother shared with me a NDE that occurred when she was hospitalized in London during WWI. She claims that she remembers traveling in a tunnel towards a light and she felt an overwhelming peace but heard a voice saying she needed to return to her body. A pediatric client I cared for told me how he had been visited by his grandmother who had died and that she was coming back soon to take him to Jesus. He shared some of the words to a song she was singing and his mother said it was the same song she used to sing to her when she was a child. She did not know if the grandmother had ever sung it to her son and if so he would have been too young at the time of her death to remember the words.

For part six of the questionnaire, we asked participants to write accounts of DBVs that they had knowledge of. Again, not all participants elected to respond to this section, but of those who did, a total of $168(29.42 \%)$ of the nurse educators described either single or multiple DBV anecdotes. Review of themes between accounts of NDEs and DBVs suggested some similar characteristics; formal thematic content analysis will be performed in a developing research article. Below are examples of just a few of these the DBV anecdotes (even in cases in which the respondent mis-labeled the experience as an NDE). 
I have had many patients tell me they have had a near death experience in which their deceased family members come to get them. I have also had an experience where a cool breeze went right thru me and it was such a calming experience as though an angel went through me as my patient died.

My father dying of cancer would feel someone sitting at the end of his bed every night and KNEW it was my (dead) mother. He felt at peace when this occurred and was comforted. He told me he had "vivid dreams" of her telling him to "let go" and the "kids" (us!) would be OK.

I specifically recall my own mother asking me who the man was in the corner. She saw him on several occasions. He would just smile at her. She wasn't afraid but she thought she knew him. She also saw many deceased relatives but could not understand why they would not speak to her. My father's death experience was 10 years after my Mom. I can only surmise that he saw something so incredible because he was unresponsive for 36 hours and just prior to his passing he woke up and with a look of wonder stared up toward the ceiling in awe. My husband said it looked as if he was saying WOW, would you look at that.

\section{Discussion}

The study revealed that most nursing faculty members considered near-death phenomena to be actual experiences that many patients encounter during traumatic health events resulting in a close brush with death or as a result of end-of-life experiences. The study also demonstrated that most nursing faculty members believed that nursing curriculum should include NDE and DBV discussion topics and that nursing students should be permitted to care for patients who had experienced NDEs and DBVs.

Item-level regression analysis of the attitude components revealed a complex set of relationships between demographic characteristics and experiences with NDEs and DBVs. Although item-level analysis precludes generalizations across the components, two key findings of this analysis are particularly noteworthy. First, and not surprisingly, a nurse educators' experiences with NDEs and DBVs were significantly related to specific items within the attitude components; however, these experiences were not necessarily associated with more positive attitudes, particularly in the caring component. For example, nurse educators who had provided care for patients and family members who had reportedly experienced DBVs were less likely to reflect positive attitudes toward caring in 12 out of 13 items in the caring component of the questionnaire. A similar finding in the general attitude component 
in which nurses with this type of experience were less likely to select responses associated with positive attitudes in 7 out of 10 items is also perplexing and runs counter to previous findings that nurse educators' experiences with NDEs have positive impacts on nursing practice (Morris \& Knafl, 2003). Although nurse educators who had provided care for patients experiencing NDEs were more likely to select only more positive responses, nurse educators who reported that a family member experienced an NDE were consistently less likely to select more positive attitudinal responses in the caring component. These counterintuitive results may be explained by the possibility that other variables may be important drivers of attitudes, such as the nature of the NDE/DBV experience, but these variables were not addressed in the questionnaire and, thus were not evaluated in the analysis. Possible clarification of this matter remains for future investigation.

A second key finding from the item-level analysis is that demographic characteristics, such as education, religion, sex, and ethnicity, were significantly related to general attitudes and attitudes toward caring. With the exception of respondent sex and religion, however, the association was not consistent across either items or components. That is, these characteristics were associated with more positive attitudes in one item and with more negative attitudes in another item within the same component. For example, doctorally-trained nurse educators were more likely to select questionnaire responses that reflected positive attitudes in only three of four items on the general attitude component of the questionnaire and in only four of six of the items on the attitudes toward care component-with their responses on the remaining item(s) reflecting more negative attitudes. Omitted demographic and other non-NDE/DBV experiential variables might explain some of the inconsistencies. For example, the finding that differences in attitudes toward NDEs may be dependent upon nurse specialty (Bucher, Wimbush, Hardie \& Hayes, 1997) may be particularly relevant to the extent that the sample is non-representative of the larger nursing workforce. Again, future research may provide elucidation.

Nurses have acknowledged the importance of providing holistic spiritual care to patients and their families; however, many nurses avoid this area of nursing care, fearing an invasion of patient privacy (Catanzaro, 2004). Researchers approaching nursing curriculum from a nursing educational leadership standpoint found evidence that nursing faculties may be remiss in providing spiritual and philosophical material in nursing curriculum (Gray, Garner, Snow, \& Wright, 2004). Gail Pittroff (2010) noted a global lack of spiritual care being 
provided by healthcare disciplines. Patients, including those who have experienced NDEs and DBVs, have indicated a lack of supportive spiritual care from nursing and healthcare professionals. Perhaps nursing faculty members who do not integrate their own spirituality into their personal and professional activities are not serving as appropriate role models to nursing students who will someday be charged with providing health care to a patient experiencing an NDE and/or a DBV (Miklancie, 2001).

According to our participants, inquiry in the area of NDEs and DBVs should be encouraged as an appropriate research agenda for nursing students. The findings reveal a need for nursing educational leaders to support the development of experiences that facilitate the mentoring and instruction of nursing students in techniques that support lifespan nursing care interventions for patients and families who incur end-of-life experiences such as NDEs and DBVs. The findings support previous research emphasizing the importance for 21st century healthcare to include spiritually-guided nursing care aspects into nursing curriculum and nursing programs (Birkenmaier, Behrman, \& Berg-Weger, 2005).

Updating curricular content to include theoretical and practical applications of NDEs and DBVs in nursing education programs may depend upon the extent to which leaders and faculty in these programs have sufficiently positive motivation and knowledge about these phenomena to drive change. Although the results of the knowledge component scores showed that most of the nurse educators were undecided with respect to the correct response to specific items in the component, with $84 \%$ of the nurse educators scoring less than $50 \%$ correct on the component and with nearly $5 \%$ scoring 0 , the scores on the knowledge component of the questionnaire certainly indicate a need for continuing education about NDEs and DBVs. Incorporation of NDE and DBV content would logically fit into fundamental and advanced medicalsurgical nursing courses that contain didactic content that includes death and dying, and Watson's (1988) model of human care supports the type of learning by which nursing educational leaders can incorporate these topics into nursing course content. However, nurse educators must have knowledge of these phenomena in order to effectively prepare student nurses to provide quality and compassionate care in clinical settings where they may encounter these experiences.

The research revealed that many nurse educators have witnessed and/or personally experienced NDEs and DBVs; as such, these phe- 
nomena have a place in the nursing program curriculum. Nursing leaders/instructors are called upon to be the facilitators and role models for nursing students, equipping them with the essential caretaking attributes, including comprehensive, competent, cultural, holistic, and spiritual care that will ultimately enhance the wellbeing of patients and families. Nursing is an art and a science, and those who have a calling for the profession need to ensure that the type of care provided at death is of the same magnitude as that provided at birth, especially for patients experiencing NDEs and DBVs. The incorporation of near-death phenomenal content, as well as mentoring by nursing faculty, will allow the opportunity for nursing students to understand and explore such events and to provide compassionate holistic care. To the extent that attitudes of leadership and instructors in nursing education programs partially drive the content-related development of programs of study in nursing education, recognition that varying attitudes associated with these phenomena exist may present an opportunity for faculties and leadership to engage in meaningful dialogue about these phenomena and how to best develop education programs.

This study involved several limitations. In addition to the concern of sample selectivity bias, a potential limitation is related to the instrument itself. Although use of the NDPKAQ was appropriate given the research agenda, the growth of research in NDEs and DBVs subsequent to the questionnaire's development calls for a revision of the questionnaire in light of more recent findings about these phenomena. Indeed, Laura Pace (2013) has recently undertaken development of an updated instrument, the Knowledge and Attitudes about Near-Death Experiences Scale (KANDES).

Based on the investigation of the study, our nursing leadership recommendations for education and clinical practice include:

- Nursing curriculum should provide opportunities in the clinical environment to include simulation experiences for nursing students to engage in discussions about NDEs and DBVs which that will enhance existential learning of the nursing students to better care for patients who have had these experiences.

- Professional nursing organizations should include break-out program sessions on near-death phenomena to healthcare providers who attend nursing conferences.

- In-service hospital programs should be offered to nursing and ancillary staff to educate on existence of near-death phenomena experiences that occurring near death within the patient population, thereby facilitating 
enhanced comprehensive and holistic care to patients and their family members across the age-span continuum.

Based on the findings of this study, our recommendations for future research include:

- Replication of the study utilizing a larger and more random sample of nursing educators.

- Replication of the study utilizing senior nursing students who have had previous theory/clinical content on death and dying.

- Replication of the study utilizing hospital nursing staff.

- Replication of the study utilizing a global sample of health care professionals.

- A qualitative study that can reveal the perspective of nurses who have experienced care for terminal patients.

- A qualitative study that investigates the perspective of relatives who care for terminally ill family members.

In conclusion, results of this study indicate that NDEs and DBVs are common occurrences in both the personal and professional lives of nurse educators. Though these educators' attitudes tended to be positive both about NDEs and about caring for patients who experience them, their knowledge of NDEs was less than ideal. All three aspect of our findings - frequency, attitudes, and knowledge-point to the importance of adding education about NDEs and DBVs to nursing curriculum, in-service programs, and conference presentations and of pursuing additional research on various aspects of these phenomena.

\section{References}

Badham, P. (1997). Religious and near-death experience in relation to belief in a future life. Mortality, 2(1), 7-21.

Barbato, M. (2009). Reflections of a setting sun: Health experiences around death. Adelaide, Australia: Griffin Press.

Barnett, L. (1991). Hospice nurses' knowledge and attitudes toward the neardeath experience. Journal of Near-Death Studies, 9(4), 225-232.

Bevis, E., \& Watson, J. (1989). Toward a caring curriculum: A new pedagogy for nursing. New York, NY: National League for Nursing.

Birkenmaier, J., Behrman, G., \& Berg-Weger, M. (2005). Integrating curriculum and practice with students and their field supervisors: reflections on spirituality and the aging (ROSA) model. Educational Gerontology, 31(10), 745-763.

Bucher, L., Wimbush, F., Hardie, T., \& Hayes, E. (1997). Near death experiences: Critical care nurses' attitudes and interventions. Dimensions of Critical Care Nursing, 16(4), 194-201.

Catanzaro, A. (2004). The meaning and place of spirituality in the education of student nurses from the mid-1800s to the present time (Doctoral disserta- 
tion). Available from ProQuest Dissertations and Theses database. (UMI No. 30791452).

Corcoran, D. (1988). Helping patients who've had near-death experiences. Nursing, 18(11), 34-39.

Cunico, L. (2001). Knowledge and attitudes of hospital nurses in Italy related to near-death experiences. Journal of Near-Death Studies, 20(1), 37-50.

Drasgow, F., \& Hulin, C. L. (1990). Item response theory. In M. D. Dunnette \& L. M. Hough (Eds.), Handbook of industrial and organizational psychology (vol. 1, pp. 577-636). Palo Alto, CA: Consulting Psychologists Press.

Fenwick, P., \& Fenwick, E. (2008). The art of dying. London, UK: Continuum.

Fenwick, P., Lovelace, H., \& Brayne, S. (2007). End of life experiences and their implications for palliative care. International Journal of Environmental Studies, 64(3), 315-323.

Flew, A. (2007). There is a God: How the world's most notorious atheist changed his mind. New York, NY: Harper Collins.

Flew, A. (2008). There is a God: How the world's most notorious atheist changed his mind [Narrated by J. P. Curless]. Frederick, MD: Recorded Books.

Flew, A. (2010). Tribute to Antony Flew from the archives. The Philosophers' Magazine. Retrieved from http://www.philosophypress.co.uk??p = 1171

Fox, M. (2003). Religion, spirituality, and the near-death experience. London, England: Routledge.

Gray, J., Garner, L., Snow, D., \& Wright, K. (2004). Spiritual perspective and needs: A comparative study of nursing faculty in a Christian university and a state university. Christian Higher Education, 3(1), 61-77.

Greyson, B. (1997). The near-death experience as a focus of clinical attention. Journal of Nervous and Mental Disease, 185(5), 327-334.

Greyson, B. (1983). The near-death experience scale: Construction, reliability, and validity. Journal of Nervous and Mental Disease, 171(6), 369-375.

Holden, J. M., Greyson, B., \& James, D. (Eds.). (2009). The handbook of neardeath experiences: Thirty years of investigation. Santa Barbara, CA: Praeger/ ABC-CLIO.

Holden, J. M., Oden, K., Kozlowski, K., Hayslip, B. (2011). Teaching about neardeath experiences: The effectiveness of using The Day I Died. Omega, 63(4), $373-388$.

Hosmer, D. W., \& Lemeshow, S. (1989). Applied logistic regression. New York, NY: Wiley Interscience.

McEvoy, M. D. (1990). The near-death experience: Implications for nursing education. Loss, Grief \& Care, 4(1-2), 51-55.

Miklancie, M. (2001). The spiritual lived experience of nurse educators within the context of their teaching practice (Doctoral dissertation). Available from ProQuest Dissertations and Theses database. (UMI No. 304768978)

Minitab 15 Statistical Software (2010). [Computer software]. State College, PA: Minitab.

Moody, R. (1975). Life after life. New York, NY: Bantam Books.

Moody, R. (2007). Near-death experiences in ancient Greek philosophy: The origins of rational inquiry into the afterlife. Position paper for the Academy of Spirituality and Paranormal Studies.

Moore, L. (1994). An assessment of physicians' knowledge and attitudes toward the near-death experience. Journal of Near-Death Studies, 13(1), 91-102. 
Morris, L. L., \& Knafl, K. (2003). The nature and meaning of the near-death experience for patients and critical care nurses. Journal of Near-Death Studies, 21(3), 139-167.

Morse, M. (1983). A near-death experience in a 7-year-old child. American Journal of Diseases of Children, 137(10), 959-961.

National League of Nursing. (2010). About the NLN. Retrieved from http://www .nln.org/aboutnln/index.htm

Oakes, R. (1981). Near-death events and critical care nursing. Topics in Clinical Nursing, 3(3), 61-78.

O'Connell, A. A. (2006). Logistic regression models for ordinal response variables. Thousand Oaks, CA: Sage.

Pace, L. (2013). Development of the Knowledge and Attitudes about Near-Death Experiences Scale (KANDES) (Unpublished doctoral dissertation). University of North Texas: Denton, TX.

Parnia, S. (2006). What happens when we die: A ground breaking study into the nature of life and death. Carlsbad, CA: Hay House.

Pittroff, G. (2010). The cultivation and practice of spiritual care expertise in an inpatient palliative care setting (Doctoral dissertation). Available from ProQuest Dissertations and Theses database. (UMI No. 823012880)

Qualtrics. (2009). Qualtrics [computer software]. Provo, UT: Qualtrics Research Suite.

Ring, K. (1980). Life at death: A scientific investigation of the near-death experience. New York, NY: Coward, McCann \& Geoghegan.

Royse, D. (1985). The near-death experience: A survey of clergy's attitudes and knowledge. Journal of Pastoral Care, 39(1), 31-42.

Sabom, M. (1982). Recollections of death: A medical investigation. New York, NY: Harper \& Row.

Streit-Horn, J. (2011). ADC fact sheet. Retrieved from http://www.eternea.org/ PDF/ADC\%20fact\%20sheet.pdf

Thornburg, N. (1988). Development of the near-death phenomena knowledge and attitudes questionnaire. Journal of Near-Death Studies, 6(4), 223-238.

Walker, B., \& Russell, R. (1989). Assessing psychologists' knowledge and attitudes toward near-death phenomena. Journal of Near-Death Studies, 8(2), $103-110$.

Watson, J. (1985). Nursing: The philosophy and science of caring. Niwot, CO: University Press of Colorado.

Watson, J. (1988). Nursing: Human science and human care: A theory of nursing. New York, NY: National League for Nursing.

Watson, J. (1994). Applying the art \& science of human caring. New York, NY: National League for Nursing Press. 